\title{
The DC Grid Reliability and Cost Evaluation with Zhoushan Five-Terminal HVDC Case Study
}

\author{
Chuanyue Li \\ Cardiff University UK \\ LiC23@cardiff.ac.uk
}

\author{
Xiaobo $\mathrm{Hu}$ \\ Electric Power Research \\ Institute China \\ huxiaobo@epri.sgcc.com.cn
}

\author{
Jingli Guo \\ Xi'an Jiaotong University \\ China \\ Guojingli.xjtu@gmail.com
}

\author{
Jun Liang \\ Cardiff University UK \\ LiangJ1@cardiff.ac.uk
}

\begin{abstract}
Multi-terminal HVDC (MTDC) is a promising technology for DC grid development. For a certain MTDC system, there are many ways to interconnect the terminals together through DC cables. Such interconnections also known as topologies influence the amount of power transmitted from generators to loads, especially in fault conditions. In order to design a reliable and cost-friendly de grid, reliability and economic will be chosen as the criteria for topology evaluation. This paper will figure out a reliability and cost evaluation method for dc grids. Zhoushan multi-terminal VSC-HVDC transmission project is given as a case study.

Index Terms-DC grids, Economics, Reliability
\end{abstract}

\section{INTRODUCTION}

Under the consideration of environment-friendly development, traditional fossil energy will be replaced by renewable energy step by step. However, renewable sources normally are far from the load center. High-Voltage Direct Current (HVDC) is a preferable technology for long-distance and bulk-power transmission.

As a newer HVDC technology, the advantages of voltage source converter based HVDC (VSC-HVDC), including power reversal without changing dc voltage polarity of the converters, individual active and reactive control, black-start capability, and no commutation failure make it more suitable for dc grids than line commutate converter based HVDC (LCC-HVDC) [1-3]. More recently, a modular multi-level VSC (MMC) has been introduced to replace the traditional concept of VSC.[4] It is capable to reach any voltage level theoretically with lower switching frequency. Its converter losses are reduced to around 1\% [5]. MMC-HVDC has become the promising technology for dc grids.

DC grid topologies are roughly classified into two groups: radial topology and meshed topology. For radial topology, there is only one transmission path between two terminals. Meshed topology gives redundancy in power flow paths, which means power can flow along an alternative path if one path is out of service. For certain terminals, there are many ways to interconnect them together through DC cables.

Suitable topology applied in the dc grid has the ability to reduce the influence of faults on the dc grid. In other words, they can increase the proportion of power received at load during fault conditions. The comparison among these topologies is mainly from two aspects, reliability and economics.

Normally reliability evaluation methods are categorized into two groups: analytical methods and simulation methods [6]. Analytical methods aim to evaluate the reliability indices by the mathematical method, like Frequency and Duration method [7]. For a complex system reliability evaluation, the disadvantage of analytical method is that a large number of mathematical analysis and calculation should be made. The idea of simulation methods like Monte Carlo method [8] is to simulate the actual process and random behaviour of the system, this method is especially convenient to evaluate the reliability indices of a complex system. The capacity outage possibility table (COPT) is used to indicate how reliable such dc grid is. COPT is the table that shows the possibility of each capacity outage state of the dc grid.

In cost evaluation, the capital cost is not the only evaluation criteria. It is necessary to consider the equivalent cost of system unavailable power. This cost is also evaluated by Monte Carlo method, as shown in Fig. 1

This paper is organised below: the dc grid reliability and cost evaluation based on Monte Carlo simulation method is proposed in Section II and Section III. Protection and operation rules of the dc grid will be considered in this method. Zhoushan five-terminal HVDC system is introduced as a case study in Section IV, the supposed meshed topology is compared with the existing radial topology. Section V presents the results of case study and the advice is given for future development of Zhoushan HVDC system. The whole evaluation system is simulated in MATLAB.

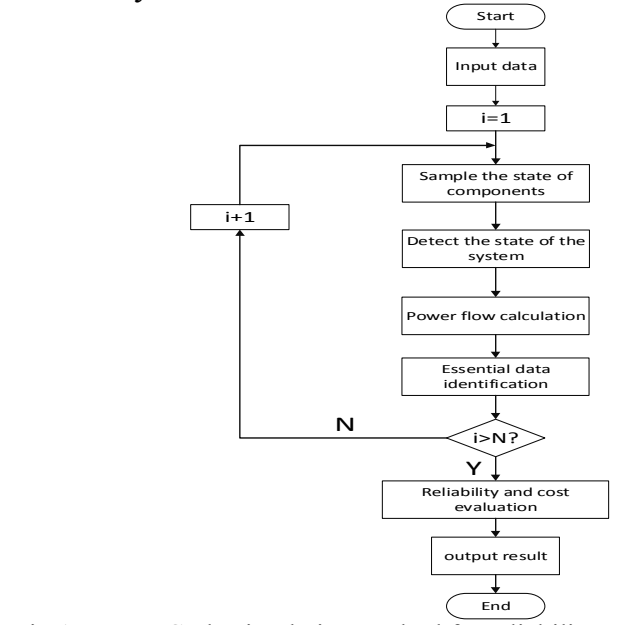

Fig.1. Monte Carlo simulation method for reliability and cost evaluation 


\section{RELIABILITY EVALUATION}

For a dc grid reliability evaluation, the DC cables, DC breakers and converters are taken into account. Up to date, there are two protection schemes for dc grids which are able to take the faulted part out of the system and keep others working. One is AC protection, the other is DC protection.

It is an economical way for dc grids to be protected by ac side without DC breakers. For AC protection no matter what $\mathrm{dc}$ fault occurs, the whole dc system is taken out firstly, and the unfaulted part goes back to service after fault isolated [10]. DC protection using DC breakers acts faster than AC protection, and allows unfaulted parts to continue [11]. It is foreseeable that DC protection will lead dc grid protection market. However, due to the lack of commercial DC breakers, $\mathrm{AC}$ protection is still an alternative approach today. In this paper, both protection schemes are considered.

For radial dc grids, a failure of any DC cable or converter results in losing one terminal permanently. For meshed dc grids, the power can flow through the alternative line when one line gets failed, but the amount of power through the alternative line depends on its capacity. If the alternative line is overload, power curtailment should be adopted. One faulted converter means one terminal is isolated. For both types of dc grids, a failure of the voltage-controlled converter makes the whole system be out of service.

The flow chart of Monte Carlo simulation method is shown in Fig.1. In a dc gird, each component has two states: work and fault. The availability of one component at working state can be calculated as below:

$$
A=M T T F /(M T T F+M T T R)
$$

A is availability of the component, MTTF is mean time to failure, MMTR is mean time to repair. MTTF and MMTR for each component of a dc grid are summarised into Table I. Due to the lack of information about the reliability data of $\mathrm{MMC}$, its reliability data is calculate according to [9].

The combination of each component's state determines the state of dc grid. After sampling the state of each component according to their availability, the state of the system is determined. In dc systems, the only relationship between current and voltage is realised by resistance. Power flow calculation based on such relationship and Kirchoff's current law is used to calculate each line's current and each node's voltage. The detail of power flow calculation will be discussed in case study.

After power flow calculation, outage power is identified as below:

$$
\begin{aligned}
P_{\text {outage }} & =P_{\text {sys }}-P_{\text {trans }} \\
P_{\text {trans }} & =I_{\text {rec }} \times V_{\text {rate }}
\end{aligned}
$$

$P_{\text {sys }}$ is rated power of system, $P_{\text {trans }}$ is actual transmitted power, $I_{r e c}$ is the total current flowing into the receiving end, $V_{\text {rate }}$ is rating voltage of the system.

Different states of the system may give same outage power value. These states are grouped into same capacity outage state. The probability of each capacity outage state is calculated below:

$$
\operatorname{Prob}_{i}=k_{i} / N
$$

$\operatorname{Prob}_{i}$ is the ith capacity outage state's probability, $k_{i}$ is the frequency of such state, $\mathrm{N}$ is total simulation frequency.
Sample size referred to $\mathrm{N}$ in Fig.1 determines the accuracy of final result. Sometimes only part of the power is transmitted to load due to the fault. Such situations are defined as performance levels of one dc grid. Expected system performance level [8] is used to figure out a reasonable sample size. When the sample size is big enough to make expected system performance level stable, reliability and cost evaluation will settle down. Its expression is shown below:

Expected Perf $(\%)=\sum_{\text {all perfermance levels }} P *$ Prob

$P$ is the transmitted power at this performance level, Prob is its probability.

\section{Cost Evaluation}

Cost evaluation under Monte Carlo simulation takes only N-1 secure into account. Capital cost is not the only standard to evaluate a dc grid. The equivalent cost caused by unavailable power due to system loss and power curtailment is seen as an alternative part of system cost, as shown below:

$$
C_{\text {total }}=C_{\text {investment }}+C_{\text {power }}+C_{C I C}
$$

$C_{\text {total }}$ is total cost of the dc grid, $C_{\text {power }}$ is equivalent cost of unavailable power, $C_{\text {investment }}$ is capital cost. CIC means the customer interruption cost.

Capital cost is computed as below:

$$
C_{\text {investment }}=N_{1} C_{\text {converter }}+N_{2} C_{\text {beaker }}+N_{3} C_{\text {cable }}
$$

$C_{\text {converter }}, C_{\text {beaker }}, C_{\text {cable }}$ are the price for each component as shown in Table II, the price of each DC breaker is supposed to be $1 / 6$ of its tied converter [14]. $N_{1}, N_{2}, N_{3}$ are the number of components that a dc grids need.

Unavailable power are categorised into three parts, and will be identified after power flow calculation in Fig.1. First part is the loss of system including converter loss, cable loss and dc breaker loss:

$$
P_{\text {loss }}=P_{\text {cable }}+P_{\text {converter }}+P_{\text {breaker }}
$$

Cable loss and breaker loss on each line are calculated as below:

$$
\left\{\begin{array}{c}
P_{\text {cable } i j}=I_{i j}^{2} R_{i j} \\
P_{\text {breaker } i j}=2 \times\left(V_{i}+V_{j}\right) \times I_{i j} \times B R K_{\text {loss_o }}
\end{array}\right.
$$

$R_{i j}$ and $I_{i j}$ are resistance and current individually between node $\mathrm{i}$ and node $\mathrm{j}$. Two DC breakers are installed for each cable normally, and their loss is related to the power flow through them. $B R K_{-}$loss_\% is loss rate of breakers.

Total converter loss is calculated as below:

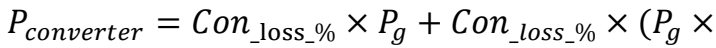

$\left(1-\right.$ Con_loss_\% $\left.\left._{1}\right)-P_{\text {cable }}-P_{\text {breaker }}\right)$

Con loss_\% $_{\text {. }}$ is loss rate of converters. $P_{g}$ is the total power of generation end.

Second one is the not-served power that is forced to be reduced due to power curtailment. Third one is not-received power that cannot be delivered to receiving end to fulfil the demand of customers due to power curtailment. In a dc grid, fault part is taken out of the grid to ensure the healthy part continue to work. Faulted converters reduce generated power or received power. Faulted cables may reduce the transmission capacity, further result in the overload of transmission system. Thus if some cable faults or converter faults occur, the generation has to do power curtailment. 
TABLE I

RELIABLE DATA OF COMPONENTS [9][12][13]

\begin{tabular}{|c|c|c|}
\hline Components & MTTF/year & MTTR/hour \\
\hline DC breaker & 20 & 50 \\
\hline Submarine cable & $28 / 100 \mathrm{~km}$ & 1440 \\
\hline Land cable & $28 / 100 \mathrm{~km}$ & 360 \\
\hline MMC & 0.468 & 40 \\
\hline
\end{tabular}

TABLE II

THE PRICE OF EACH COMPONENT [14][15]

\begin{tabular}{|c|c|}
\hline Converter & Cable \\
\hline $0.0816 \mathrm{M} / \mathrm{MVA}$ & $0.00128 \mathrm{M} /(\mathrm{km} * \mathrm{MW})$ \\
\hline
\end{tabular}

Actually both values of not-served power and not-received power are equal as shown below:

$$
P_{\text {not-served }}=P_{\text {not-received }}=P_{\text {sys }}-P_{\text {trans }}
$$

These three parts of unavailable power bring economic loss to transmission system, generation and customer individually, as shown blew:

$$
C_{\text {power }}=C_{\text {loss }}+C_{\text {not-served }}
$$

$C_{\text {loss }}, C_{\text {not-served }}, C_{C I C}$ are due to system loss, not-served power and not-received power.

$C_{\text {loss }}$ and $C_{\text {not-served }}$ can be calculated as the Net Present Value (NPV), because the electricity price always maintains the same as shown blow:

Cost $=$ power $\times$ hour $\times$ price $\times\left(\sum_{t=1}^{\text {life }} \frac{1}{(1+\text { interest })^{t}}\right)(12)$ Power is system loss or not-served power, hour is working time of the system per year, price is electricity price, life is economic life (unit: year) of the system.

The growth of local economy makes CIC increase year by year. The increase rate is supposed to be equal to interest, therefore the expression of $C_{C I C}$ is simplified:

$$
C_{C I C}=\text { power } \times \text { hour } \times \text { CIC } \times \text { life }
$$

Power in (13) means not-received power.

Power flow under different state of system is different, which gives various system loss, not-served power and notreceived power. The expectation method is used and the power is computed as below:

$$
\begin{gathered}
P_{\text {loss }}=\sum_{i=0}^{N} P_{\text {loss } \__{-}} \times \operatorname{Prob}_{i} \\
P_{\text {not-served }}=\sum_{i=0}^{N} P_{\text {not-served } i} \times \operatorname{Prob}_{i} \\
P_{C I C}=P_{\text {not-served }}
\end{gathered}
$$

$\mathrm{i}$ means one state of the system, $\mathrm{N}$ is the whole states of the system under N-1 secure.

\section{CASE STUdy: ZhOUSHAN FIVE-TERMINAL MMC-HVDC}

Zhoushan $\pm 200 \mathrm{kV}$ MMC-HVDC is the first five-terminal dc grid in the world as shown in Fig. 2, and has been put into operation in 2014. This dc grid is built to meet the increasing electricity demand of islands near Ningbo. As sending end, the substation on Zhoushan island is to transmit electricity from Ningbo main ac grid to Daishang island, Qushan island, Yangshan island and Siqiao island. Daishan substation is a 100MW receiving end under normal operation. Due to a 220 $\mathrm{kV}$ ac link between Zhoushan island and Daishan island, Daishan substation is able to be an alternative $300 \mathrm{MW}$ sending end when Zhoushan substation is out of service. Each substation is in parallel connection to the dc grid. Therefore, the loss of any power controlled converter will not influence the continuous operation of Zhoushan dc grid. Radial topology is adopted and no dc breakers are used. A meshed

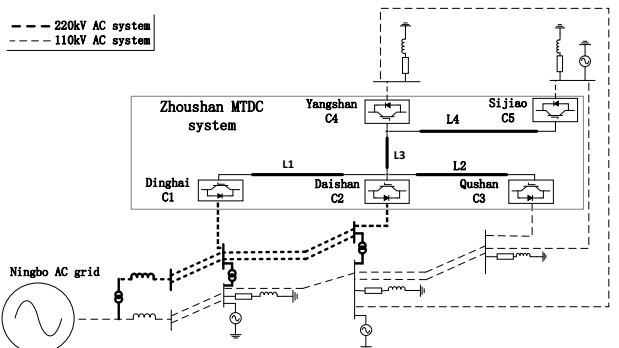

Fig.2. Zhoushan five-terminal MMC-HVDC system

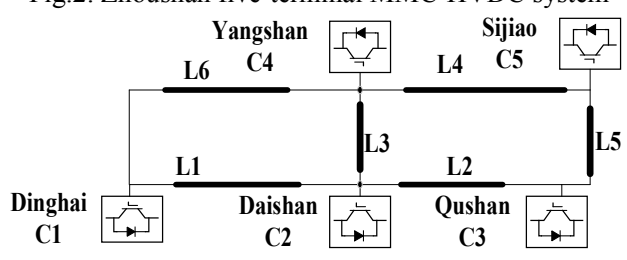

Fig.3. Meshed Zhoushan dc grid

topology is proposed as an upgrading scheme in the future, as shown in Fig.3.

\section{A. Data and assumption}

In normal operation, $\mathrm{C} 1$ regulates the voltage and the others control the power. When $\mathrm{C} 1$ is out of service, $\mathrm{C} 2$ take over the control of voltage. Symmetrical monopole needs two DC cables to connect positive pole and negative pole individually. Each dc line in Fig. 2 and Fig. 3 stands for two DC cables actually, and needs four DC breakers. The failure of any component leads to the complete loss of the line. Thus, such two DC cables can be seen as series connection. The resistance and length of each line is the sum of these two cables. The overall data of Zhoushan de grid is summarised into Table III.

For a radial topology, any dc fault causes the loss of corresponding end. Therefore power flow in other lines will not be influenced. For a mesh topology, cable fault may result in the overload of alternative line. Thus, two sets of cable capacity are proposed in this meshed topology. Three cases are given below for reliability and cost evaluation:

- A1: Radial topology

- A2: Meshed topology

- A3: Enhanced A2

A1 is the existing topology of Zhoushan dc grid. A2 is the meshed topology with cable overload concerns under some fault conditions. Both A2 and A3 share the same topology, but A3 has lager cable capacity without overload concerns under any fault condition. The data of A1-A3 is summarized into Table III, and the assumptions for these three cases are shown below.

Assumptions for A1: (1) A constant average electricity demand $(70 \%)$ is considered, because the electricity demand of customers is variable during a day. (2) AC protection is used. As mentioned in [10], the whole dc grid will be out of service for $0.7 \mathrm{~s}$ to clear each dc fault. The impact of such $0.7 \mathrm{~s}$ on customers is ignored. (3) Each line is considered as one component, its availability is $A_{\text {cable }}^{2}$.

Assumptions for A2: (1) A constant average electricity demand $(70 \%)$ is considered. (2) DC protection is used with DC breakers. Two DC breakers are installed for each cable. Four DC breakers will be used on each line due to symmetrical monopole structure. The loss of DC breaker is supposed to $0.01 \%$, because the DC breaker proposed in [16] 
Table III

ZHOUSHAN FIVE-TERMINAL MMC-HVDC DATABASE

\begin{tabular}{|c|c|c|c|}
\hline \multirow{4}{*}{$\begin{array}{c}\text { Converter } \\
\text { (MMC) }\end{array}$} & Structure & \multicolumn{2}{|c|}{ Symmetrical monopole } \\
\hline & Control & \multicolumn{2}{|c|}{ Voltage control: C1, C2(backup) } \\
\hline & strategy & \multicolumn{2}{|c|}{ Power control: $\mathrm{C} 2, \mathrm{C} 3, \mathrm{C} 4, \mathrm{C} 5$} \\
\hline & Capacity & \multicolumn{2}{|c|}{ C1:400MW; C2:300MW; C3-C5:100MW } \\
\hline \multicolumn{2}{|c|}{ Current safe range } & \multicolumn{2}{|c|}{ Maximum $110 \%$ of rating current of each cable } \\
\hline \multicolumn{2}{|c|}{ Voltage level } & \multicolumn{2}{|c|}{ $\pm 200 \mathrm{kV}$} \\
\hline \multicolumn{2}{|c|}{ Line } & Resistance and distance & Rating current \\
\hline \multicolumn{2}{|c|}{ L1 } & $1.83 \Omega / 104 \mathrm{~km}$ & $1 \mathrm{kA}$ \\
\hline \multicolumn{2}{|c|}{$\mathrm{L} 2$} & $1.92 \Omega / 32 \mathrm{~km}$ & $0.3 \mathrm{kA}$ \\
\hline \multicolumn{2}{|c|}{$\mathrm{L} 2 / \mathrm{A} 3$} & $1.17 \Omega / 32 \mathrm{~km}$ & $0.5 \mathrm{kA}$ \\
\hline \multicolumn{2}{|c|}{ L3 } & $2.85 \Omega / 77.8 \mathrm{~km}$ & $0.5 \mathrm{kA}$ \\
\hline \multicolumn{2}{|c|}{ L4 } & $4.03 \Omega / 67 \mathrm{~km}$ & $0.3 \mathrm{kA}$ \\
\hline \multicolumn{2}{|c|}{$\mathrm{L} 4 / \mathrm{A} 3$} & $2.45 \Omega / 67 \mathrm{~km}$ & $0.5 \mathrm{kA}$ \\
\hline \multicolumn{2}{|c|}{ L5 } & $3.61 \Omega / 60 \mathrm{~km}$ & $0.3 \mathrm{kA}$ \\
\hline \multicolumn{2}{|c|}{$\mathrm{L} 5 / \mathrm{A} 3$} & $2.20 \Omega / 60 \mathrm{~km}$ & $0.5 \mathrm{kA}$ \\
\hline \multicolumn{2}{|c|}{ L6 } & $2.53 \Omega / 144 \mathrm{~km}$ & $1 \mathrm{kA}$ \\
\hline
\end{tabular}

is almost lossless. (3) Submarine cables are used for L5 and L6, resistances and current rates are shown in Table III. (4) Each line is considered as one component, its availability is $A_{\text {cable }}^{2} A_{D C \text { breaker. }}^{4}$.

Assumptions for A3: (1) capacities of L2, L4 and L5 are all expanded to $0.5 \mathrm{kA}$. Other assumptions are same with A2's.

\section{B. Power flow calculation}

Different states of the system own different power flow. It is impossible for each state to calculate its power flow. Take the meshed topology as an example, 11 components are used in this dc grid including 5 converters and $6 \mathrm{dc}$ lines, there should be $2^{11}$ states. Thus a simplified power flow calculation method is proposed to be able to do power flow calculation under any state of the system, as shown in Fig. 4. It has two steps, firstly establish a standard power flow calculation model (SPFM); secondly according to the state of the system, modify the known parameters of SPFM to match its power flow calculation. The meshed topology is used to explain this method. A1 uses the same method which will not be shown again.

Normal operation is chose as the basic state to establish SPFM. Due to the voltage control capability of $\mathrm{C} 2$, fourterminal operation is chose as another basic state in case of the absence of $\mathrm{C} 1$. Thus two SPFM are built as shown in (14), (15) Fig.5, Fig.6 and Table IV. (14) is used for fiveterminal SPFM, (15) is used for four-terminal SPFM.

Three modifications are applied to SPFM, detailed modifications for meshed topology are provided in Appendix.

- $\quad 1^{\text {st }}$ modification: if $L_{i}=0$, then $R_{i}=\infty$; if $C_{i}=0$, then $I_{i}=0$.

- $\quad 2^{\text {nd }}$ modification: if the lines all connecting to the converter are in fault, the current flow into that converter should be set to zero. Take Fig. 4 as an example, if $L_{4}=0 \& L_{5}=0$, then $I_{5}=0$.

- $\quad 3^{\text {rd }}$ modification: when cable overload occurred, power curtailment will be done on the receiving end until the power of the cable is in safe range.
The data of economic evaluation for Zhoushan fiveterminal system is proposed in Table $\mathrm{V}$.

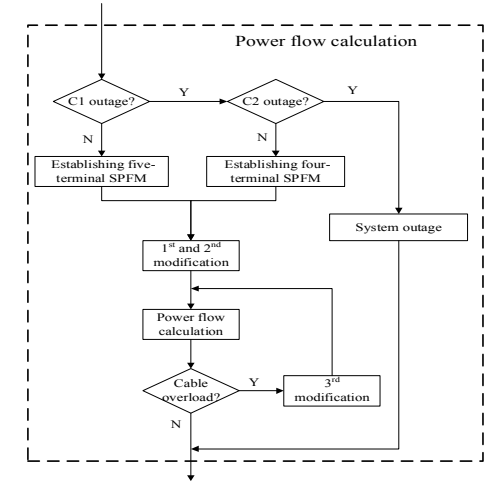

Fig.4. Power flow calculation process for Meshed topology

Table IV

POWER FLOW MODEL

\begin{tabular}{|cc|c|}
\hline \multicolumn{3}{|c|}{ Five-terminal SPFM } \\
\hline \multicolumn{2}{|c|}{ Known parameters } & Unknown parameters \\
\hline$I_{2}=0.175 \mathrm{kA}$ & $R_{2}=1.17 \Omega(A 3)$ & \\
$I_{3}=0.175 \mathrm{kA}$ & $R_{3}=2.85 \Omega$ & \\
$I_{4}=0.175 \mathrm{kA}$ & $R_{4}=4.03 \Omega(A 2)$ & $V_{2} V_{3} V_{4} V_{5}$ \\
$I_{5}=0.175 \mathrm{kA}$ & $R_{4}=2.45 \Omega(A 3)$ & $I_{6} I_{7} I_{8} I_{9} I_{10} I_{11}$ \\
$V_{1}=400 \mathrm{kV}$ & $R_{5}=3.61 \Omega(A 2)$ & $I_{1}$ \\
$R_{1}=1.83 \Omega$ & $R_{5}=2.20 \Omega(A 3)$ & \\
$R_{2}=1.92 \Omega(A 2)$ & $R_{6}=2.53 \Omega$ & \\
\hline \multicolumn{3}{|c|}{ Four-terminal SPFM } \\
\hline \multicolumn{3}{|c|}{ Known parameters } \\
\hline$I_{3}=0.175 \mathrm{kA}$ & $R_{3}=2.85 \Omega$ & Unknown parameters \\
$I_{4}=0.175 \mathrm{kA}$ & $R_{4}=4.03 \Omega(A 2)$ & $V_{2} V_{3} V_{4} V_{5}$ \\
$I_{5}=0.175 \mathrm{kA}$ & $R_{4}=2.45 \Omega(A 3)$ & $I_{6} I_{7} I_{8} I_{9} I_{10} I_{11}$ \\
$V_{2}=400 \mathrm{kV}$ & $R_{5}=3.61 \Omega(A 2)$ & $I_{2}$ \\
$R_{1}=1.83 \Omega$ & $R_{5}=2.20 \Omega(A 3)$ & \\
$R_{2}=1.92 \Omega(A 2)$ & $R_{6}=2.53 \Omega$ & \\
$R_{2}=1.17 \Omega(A 3)$ &
\end{tabular}

$I_{6} R_{1}=V_{1}-V_{2}$

$I_{7} R_{2}=V_{2}-V_{3} \quad I_{1}=I_{6}+I_{11}$

$I_{8} R_{3}=V_{2}-V_{4} \quad I_{2}=I_{6}-I_{7}-I_{8}$

$I_{9} R_{4}=V_{4}-V_{5} \quad I_{3}=I_{7}-I_{10}$

$I_{10} R_{5}=V_{3}-V_{5} \quad I_{4}=I_{11}+I_{8}-I_{9}$

$I_{11} R_{6}=V_{1}-V_{4} \quad I_{5}=I_{9}+I_{10}$

$I_{6} R_{1}=V_{1}-V_{2} \quad 0=I_{6}+I_{11}$

$I_{7} R_{2}=V_{2}-V_{3} \quad I_{2}=I_{6}-I_{7}-I_{8}$

$I_{8} R_{3}=V_{2}-V_{4} \quad I_{2}=I_{6}=I_{7}-I_{10}$

$\begin{aligned} & I_{9} R_{4}=V_{4}-V_{5} \\ & I_{10} R_{5}=V_{3}-V_{5}\end{aligned} I_{4}=I_{11}+I_{8}-I_{9}$

$I_{11} R_{6}=V_{1}-V_{4} \quad I_{5}=I_{9}+I_{10}$

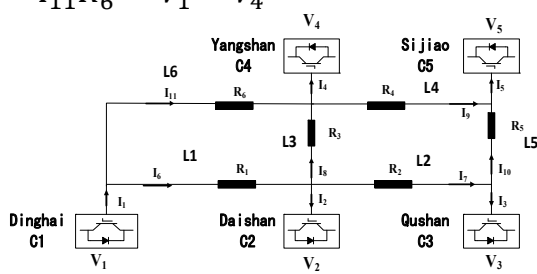

Fig.5. Five-terminal SPFM

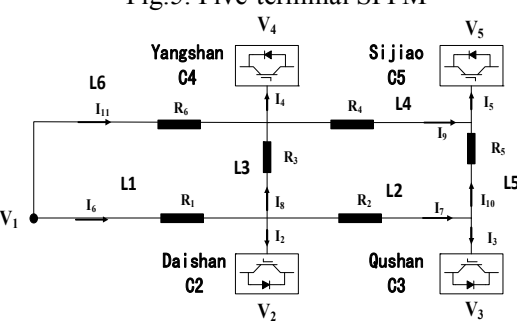

Fig.6. Four-terminal SPFM 
TABLE IX

EXPECTED UNAVAILABLE POWER AND COST EVALUATION RESULTS

\begin{tabular}{|c|c|c|c|c|c|c|c|c|c|}
\hline Case & $P_{\text {cable }} / \mathrm{MW}$ & $P_{\text {converter }} / \mathrm{MW}$ & $P_{\text {breaker }} / \mathrm{MW}$ & $P_{\text {not-served }} / \mathrm{MW}$ & $P_{\text {not-received }} / \mathrm{MW}$ & $C_{\text {Power }} / \mathrm{M} £$ & $C_{\text {investment }} / \mathrm{M}$ & $C_{\text {CIC }} / \mathrm{M}$ & $\begin{array}{c}\text { Total } \\
\text { cost } / \mathrm{M} £\end{array}$ \\
\hline A1 & 1.3793 & 5.4498 & $/$ & 4.9289 & 4.9289 & 158.3359 & 167.4368 & 387.2999 & 713.0726 \\
\hline $\mathrm{A} 2$ & 0.6856 & 5.4800 & 0.0871 & 3.3805 & 3.3805 & 129.7227 & 285.8368 & 265.6287 & 681.1881 \\
\hline $\mathrm{A} 3$ & 0.6210 & 5.4873 & 0.0872 & 3.2762 & 3.2762 & 127.5481 & 312.7168 & 239.2896 & 679.5545 \\
\hline
\end{tabular}

TABLE V

DATA FOR ECONOMIC EVALUATION

\begin{tabular}{|c|c|c|c|c|}
\hline Electricity price & interest & life/y & hour/h & CIC \\
\hline $100 £ / M W$ & $5 \%$ & 30 & 8760 & $0.299 £ / k W h$ \\
\hline
\end{tabular}

\section{RESUlt AND ANALYSIS}

Compared with A1 and A3, A2 has more states of the system due to cable capacity limit. Thus, the expected system performance level of A2 is chose as the standards for sample size identification. As shown in Fig. 7, when the sample size is more than 300 thousands, expected system performance level is stable. And the actual simple size is set to 1 million.

For the reliability evaluation, COPTs of A1, A2 and A3 are shown in Table VI, Table VII and Table VIII individually. $0 \%$ capacity outage power means all of the power is sent to receiving end. $100 \%$ capacity outage power means the whole system is out of service. Compared with radial topology A1, both meshed topologies increase the probability of $0 \%$ capacity outage power condition. Furthermore, expected capacity outage powers for each topology are $1.867 \%$ (A1), $1.31 \%$ (A2) and $1.183 \%$ (A3). It is obvious that the reliability of meshed topology is better than the reliability of radial topology due to the extra transmission lines. In meshed topologies, A2 owns more capacity outage power levels. Because the capacities of L2, L4 and L5 are not rich enough to cope with every state of the system, power curtailment has to be done when these three lines are overload. In A3, the capacities of L2, L4 and L5 are expanded. Any cable fault will not lead to power curtailment and the capacity outage power levels are reduced. A3's reliability is better than A2's due to the expanded line capacity.

Expected unavailable power is shown in Table IX. Thanks to the applied AC protection, DC breaker's loss is not considered in A1. For meshed topologies, extra lines added share the demanded power and reduce the power flow in each line, thus the cable loss is reduced compared with A1. When cable fault occurs, the power can flow through alternative transmission line. Therefore, not-served powers and notreceived powers of meshed topologies are reduced compared with radial topology. Expanded line capacities of A3 allow further reduction of the power mentioned before.

For cost evaluation as shown in Table IX, the investment cost of A3 is highest due to the expanded extra lines and DC breakers. However, thanks to these lines, the power loss cost and customer interruption cost are lowest. In cost evaluation, the disadvantage as mentioned in second assumption for A1 is ignored. If this impact is considered, the total cost of A1 will increase. Sum of these two parts gives total cost. It shows that $\mathrm{A} 3$ is most economical.
No matter from reliability evaluation or cost evaluation, A3 is the best choice for future dc grid development.

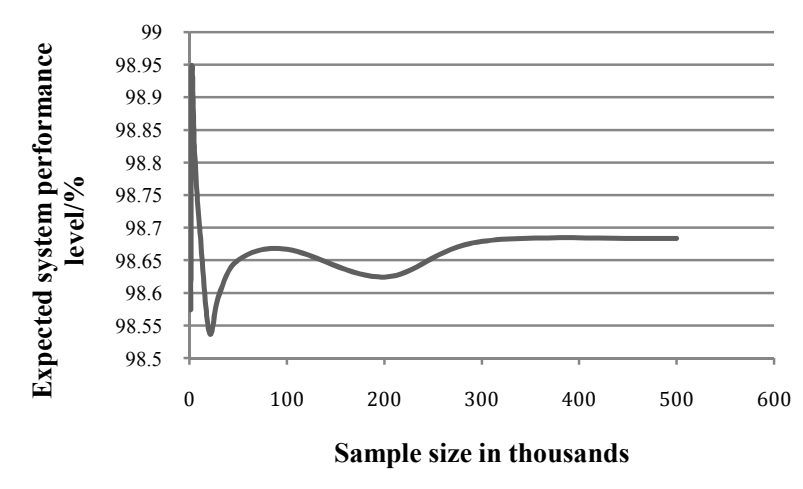

Fig.7. Expected system performance level of A2

TABLE VI

COPT OF A1

\begin{tabular}{|c|c|}
\hline Capacity outage power level $/ \%$ & Probability $/ \%$ \\
\hline $0 \%$ & 93.3287 \\
\hline $25 \%$ & 5.9297 \\
\hline $50 \%$ & 0.7016 \\
\hline $75 \%$ & 0.0258 \\
\hline $100 \%$ & 0.0142 \\
\hline
\end{tabular}

TABLE VII

COPT OF A2

\begin{tabular}{|c|c|}
\hline Capacity outage power level/\% & Probability $/ \%$ \\
\hline $0 \%$ & 94.5159 \\
\hline $14.3 \%$ & 0.8587 \\
\hline $25 \%$ & 4.5046 \\
\hline $39.3 \%$ & 0.0330 \\
\hline $50 \%$ & 0.0779 \\
\hline $64.3 \%$ & 0.0006 \\
\hline $75 \%$ & 0.0008 \\
\hline $100 \%$ & 0.0085 \\
\hline
\end{tabular}

TABLE VII

COPT OF A3

\begin{tabular}{|c|c|}
\hline Capacity outage power level $/ \%$ & Probability $/ \%$ \\
\hline $0 \%$ & 95.3746 \\
\hline $25 \%$ & 4.5376 \\
\hline $50 \%$ & 0.0785 \\
\hline $75 \%$ & 0.0008 \\
\hline $100 \%$ & 0.0085 \\
\hline
\end{tabular}

\section{ACKNOWLEDGEMENTS}

This work is supported China Electric Power Research Institute under the project XTB51201302929 and Engineering and Physical Sciences Research Council (EPSRC) under the project Enhanced Renewable Integration through Flexible Transmission Options (ERIFT) programme under Grant 
EP/K006312/1. Chuanyue Li's work is supported by China Scholarship Council under the project 201408060016. Jingli Guo's work is also supported by China Scholarship Council under the project 201406280115.

\section{CONCLUSION}

Reliability and cost evaluation method of the dc grid has been proposed in this paper. Zhoushan 5-terminal HVDC system is used as a case study. In this case study, radial and meshed topologies are compared and the influence of cable capacity is discussed. In order to achieve the reliability and cost evaluation, power flow calculation and its modifications are made. a meshed topology with expanded dc cables is identified based on this method for the future dc grid development of Zhoushan five-terminal HVDC system.

\section{REFERENCE}

[1] H. Ergun, J. Beerten and D. V. Hertem, "Building a new overlay grid for Europe," in IEEE Power. Eng. Soc. Gen. Meeting, San Diego, CA, July 2012 .

[2] Friends Of the Supergrid, "Roadmap to the Supergrid Technologies," Tech. Rep., March 2012

[3] A. Lesnicar and R. Marquardt, "An innovative modular multilevel converter topology suitable for a wide power range," in IEEE Power Tech. Conf., Bologna, Italy, June. 2003.

[4] J. Liang, T. Jing, O. Gomis-Bellmunt, J. Ekanayake and N. Jenkins, "Operation and Control of Multiterminal HVDC Transmission for Offshore Wind Farms," IEEE Trans. Power Del., vol. 26, no. 4, pp. 2596-2604, June 2011

[5] C. Oates and C. Davidson, "A comparison of two methods of estimating losses in the Modular Multi-Level Converter," in 14th Eur. Conf. on Power Electron. Appl., Birmingham, UK, Aug. 2011.

[6] R. Billinton and R. N. Allan, Reliability Evaluation of Power Systems, 2nd ed., New York: Plenum Press, 1994, pp.6-7.

[7] S. Zadkhast, M. Fotuhi-Firuzabad, F. Aminifar, R. Billinton, S. O. Faried, and A. A. Edris, "Reliability Evaluation of an HVDC Transmission System Tapped by a VSC Station," IEEE Trans. Power Delivery, vol. 25, pp. 1962-1970, 2010.

[8] R. Billinton and A. Sankarakrishnan, "Adequacy assessment of composite power systems with HVDC links using Monte Carlo Simulation." IEEE Trans. Power Syst., vol. 9, no. 3, pp. 1626-1633, August 1994.

[9] J. Guo, X. Wang, Z. Bie and Y. Hou, "Reliability modeling an evaluation of VSC-HVDC transmission system," in 2014 IEEE PES General Meeting, National Harbor, MD, 27-31 July 2014.

[10] L. Tang and B.-T. Ooi, "Locating and Isolating DC Faults in MultiTerminal DC Systems," IEEE Trans. Power Delivery., vol. 22, no. 3, pp. 1877-1884, Jul. 2007

[11] J. Candelaria and J. Park, "VSC-HVDC system protection: A review of current methods," Power System Conference and Exposition (PSCE), Phoenix, AZ, 20-23 Mar. 2011.

[12] Cigre Group B1.10, "Update of Service Experience of HV Underground and Submarine Cable Systems," Tech. Rep., Apr. 2009.

[13] S. Wang, J. Liang, and J. Ekanayake, "Optimised Topology Design and Comparison for Offshore Transmission," $47^{\text {th }}$ International Universities Power Engineering Conference (UPEC 2012), London, UK, 4-7 Sep. 2012

[14] Cigre Group B4.52, “HVDC Grid Feasibility Study,” Tech. Rep., Apr. 2013

[15] D. Westermann, D. Van Hertem, and G. Real, "Voltage Source Converter (VSC) HVDC for Power Transmission-Economic Aspects and Comparison with other AC and DC Technologies, " Working Group B4.46, Cigre, April. 2012.

[16] J. Häfner and B. Jacobson, "Proactive Hybrid HVDC Breakers - A key Innovation for Reliable HVDC Grids," CIGRE Paper., 2011.

\section{APPENDIX}

The modification of A3 is same with the modification of A2 without the $3^{\text {rd }}$ modification, because the cable capacity of A3 is expanded. The detailed modification for A2 is shown in Table X.
TABLE X

MESHED TOPOLOGY MODIFICATION FOR A2

\begin{tabular}{|c|c|}
\hline $\begin{array}{l}\text { 5-terminal } \\
\text { SPFM }\end{array}$ & Known parameters' modification \\
\hline $1^{\text {st }}$ modification & $\begin{array}{c}L_{i}=0 \rightarrow R_{i}=\infty \Omega \\
C_{j}=0 \rightarrow I_{j}=0 A \\
i=1-6, j=2-5\end{array}$ \\
\hline $2^{\text {nd }}$ modification & $\begin{array}{c}L_{1} L_{2} L_{3}=000 \rightarrow I_{2}=0 \mathrm{~A} \\
L_{3} L_{4} L_{6}=000 \rightarrow I_{4}=0 \mathrm{~A} \\
L_{4} L_{5}=00 \rightarrow I_{5}=0 \mathrm{~A} \\
L_{2} L_{5}=00 \rightarrow I_{3}=0 \mathrm{~A} \\
L_{3} L_{5} L_{6}=000 \rightarrow I_{4}=I_{5}=0 \mathrm{~A} \\
L_{1} L_{3} L_{5}=000 \rightarrow I_{2}=I_{3}=0 \mathrm{~A} \\
L_{2} L_{4}=00 \rightarrow I_{3}=I_{5}=0 \mathrm{~A}\end{array}$ \\
\hline $3^{\text {rd }}$ modification & $\begin{array}{l}\text { If } I_{7} \text { or } I_{9}=0.35 \mathrm{~A} \\
\text { The total demanded power of } \mathrm{C} 3 \text { and } \mathrm{C} 5 \\
\text { reduces to } 100 \mathrm{MW} \\
\text { If } I_{7} \text { or } I_{9}=0.525 \mathrm{~A} \\
\text { The total demanded power of } \mathrm{C} 2 \text { (or } \\
\text { C4)、 } \mathrm{C} 3 \text { and } \mathrm{C} 5 \text { reduces to } 100 \mathrm{MW}\end{array}$ \\
\hline $\begin{array}{l}\text { 4-terminal } \\
\text { SPFM }\end{array}$ & Known parameters' modification \\
\hline $1^{\text {st }}$ modification & $\begin{array}{c}L_{i}=0 \rightarrow R_{i}=\infty \Omega \\
C_{j}=0 \rightarrow I_{j}=0 A \\
i=1-6, j=3-5\end{array}$ \\
\hline $2^{\text {nd }}$ modification & $\begin{array}{c}L_{3} L_{4}=00 \&\left(L_{1} \text { or } L_{6}=0\right) \rightarrow I_{4}=0 \mathrm{~A} \\
L_{3} L_{5}=00 \&\left(L_{1} \text { or } L_{6}=0\right) \rightarrow I_{4}=I_{5}=0 \mathrm{~A} \\
L_{4} L_{5}=00 \rightarrow I_{5}=0 \mathrm{~A} \\
L_{2} L_{5}=00 \rightarrow I_{3}=0 \mathrm{~A} \\
L_{2} L_{4}=00 \rightarrow I_{3}=I_{5}=0 \mathrm{~A}\end{array}$ \\
\hline $3^{\text {rd }}$ modification & $\begin{array}{l}\text { If } I_{7} \text { or } I_{9}=0.35 \mathrm{~A} \\
\text { The total demanded power of } \mathrm{C} 3 \text { and } \mathrm{C} 5 \\
\text { reduces to } 100 \mathrm{MW} \\
\text { If } I_{7}=0.525 \mathrm{~A} \\
\text { The total demanded power of C3、C4 and } \\
\text { C5 reduces to } 100 \mathrm{MW}\end{array}$ \\
\hline
\end{tabular}

